\title{
Impacto estratégico dos fatores \\ macroambientais no desempenho de \\ concessões de serviços públicos: a CEG e a CEG RIO na ótica relacional*
}

\author{
Sérgio A. P. Bastos** \\ T. Diana L. v. A. de Macedo-Soares***
}

SuMÁRIO: 1. Introdução; 2. Referencial teórico; 3. Metodologia; 4. Resultados; 5. Discussão; 6. Conclusão e recomendações.

SuMMARY: 1. Introduction; 2. Theoretical framework; 3. Method; 4. Results; 5. Discussion; 6. Conclusion and recommendations.

Palavras-ChaVe: estratégia; planejamento estratégico; gestão estratégica; concessões; distribuição de gás canalizado; fatores macroambientais; alianças estratégicas.

KEY WORDS: strategy; strategic planning; strategic management; concessions; piped gas distribution; macro-environmental factors; strategic alliances.

O amplo rearranjo institucional e de mercado decorrente das privatizações de concessões de serviços públicos no Brasil em diversos setores econômicos tornou evidente a crescente necessidade de estabelecer ações de gestão que produzam o desempenho esperado dessas concessões. Inseridas num ambiente de incertezas, concessões como as de distribuição de gás canalizado têm sido pouco investigadas por pesquisadores no âmbito da gestão estratégica. Dentro de uma perspectiva relacional, o estudo investigou o impacto dos fatores macroambientais no desempenho da CEG e da CEG RIO, distribuidoras de gás canalizado do estado do Rio de Janeiro, privati-

\footnotetext{
* Artigo recebido em nov. 2006 e aceito em abr. 2007.

** M.Sc. Consultor de empresas na Substantiva Consultoria. Endereço: Rua Eduardo Guinle, 28/705 — Botafogo — CEP 22.260-090, Rio de Janeiro, RJ, Brasil. E-mail: sapbastos@gmail.com. *** PhD. Professor do IAG/PUC-Rio. Endereço: Rua Marquês de São Vicente, 225 — Gávea CEP 22453-900, Rio de Janeiro, RJ, Brasil. E-mail: redes@strategy-research.com.
} 
zadas em julho de 1997. De acordo com a metodologia de estudo de caso de Yin (1994), foi adotada a estratégia de triangulação dos métodos. Os dados foram coletados por meio de investigação documental/telematizada, levantamento de percepções tipo survey via questionário predominantemente estruturado e entrevistas complementares. A interpretação e a análise dos dados foram realizadas com base em referenciais teóricos relacionais e com o auxílio do modelo de análise estratégica relacional de MacedoSoares (2002). Os resultados sugeriram a adequação estratégica das empresas e confirmaram que a ótica relacional agregou valor no sentido de trazer novos insights para a tomada de decisão estratégica da CEG e da CEG RIO, em particular, e para concessões de serviços públicos, de uma forma geral.

Strategic impact of macro-environmental factors on the performance of public utility concessions: CEG and CEG RIO from a relational perspective

The wide institutional and market reorganization that resulted from the privatization of public utility concessions in Brazil in several economic sectors made evident the increasing need to take strategic business initiatives with a view to attaining the expected performance from these concessions. Embedded in uncertainties, concessions such as piped gas distribution have been hardly considered in strategic management research. From a relational perspective this study investigated the impact of macro-environmental factors on the performance of CEG and CEG RIO - gas distribution companies in the state of Rio de Janeiro, Brazil, privatized in July, 1997. In accordance with Yin's case study method (1994), a triangulation of methods was adopted. Thus, data was collected by way of documental/telematic investigations, a survey of management perceptions with the help of a predominantly structured questionnaire and complementary interviews. Data interpretation and analysis were carried out with the help of a relational framework and Macedo-Soares's model (2002) for relational strategic analysis. The results suggested that the firms' strategies were indeed adequate, confirming that the relational perspective added value to the traditional perspective, contributing with new insights to the companies' strategic decision-making processes and to the management of public utility concessions in general.

\section{Introdução}

Grandes mudanças ocorreram no setor de infra-estrutura no Brasil a partir de 1995. Em função da necessidade de transferir para a iniciativa privada a responsabilidade e o ônus pelo investimento em infra-estrutura do país e substi- 
tuir o Estado no papel de investidor, a administração do presidente Fernando Henrique Cardoso patrocinou um amplo processo de privatização, e paralela mudança nos aspectos institucionais para suportar uma nova lógica de mercado concorrencial, no lugar do monopólio estatal em diversos setores da economia brasileira. Setores como o siderúrgico, o bancário e o de concessões de serviços públicos (telecomunicações, energia elétrica, distribuição de gás etc.) foram bastante mais afetados.

Com base no art. 25, §2 e no art. 175 da Constituição da República, foi promovida uma ampla desestatização, compreendendo a alienação do controle acionário de empresas estatais nos âmbitos federal, estadual e municipal, e a outorga de concessões de serviços públicos. O setor de distribuição de gás canalizado no estado do Rio de Janeiro, objeto deste artigo, insere-se nesse contexto.

Foram dois os pilares que sustentaram a passagem do controle de concessões de serviços públicos à iniciativa privada: um arcabouço legal, compreendido por uma nova e forte legislação; e um arcabouço regulatório, à parte da administração pública direta, com a criação das agências reguladoras. Rocha (2003:223) lembra que,

a partir do momento em que o Estado delega a terceiros a exploração da atividade econômica, em lugar de desempenhá-la diretamente, tornou-se necessário a criação ou o reforço de aparato institucional responsável especificamente por assegurar, no interesse da sociedade, a adequada prestação dos serviços públicos.

Três grandes grupos de interesse atuam no setor de infra-estrutura e, particularmente, nos serviços públicos concedidos, como é o caso da distribuição de gás canalizado: o poder concedente, o conjunto de investidores/gestores das concessionárias e os consumidores. Com o papel de preservar o equilíbrio entre esses grupos, evitando o benefício de um agente em detrimento dos demais, dentro de um ambiente regulatório derivado da legislação em vigor, faz-se necessária a figura de um agente regulador competente para lhe dar os contornos. Em muitos países, esse poder, com suas funções decorrentes, é exercido por órgão no âmbito do próprio poder concedente. No Brasil, como em outros países, foi criada a instituição de agentes reguladores, no âmbito dos governos federal, estadual ou municipal para a gestão das atividades regulatórias.

Destaque-se, no caso do Brasil, a passagem do controle de empresas concessionárias de serviços públicos ao setor privado sem que o marco regulatório estivesse totalmente estabelecido. Num ambiente institucional estável, a atuação dos gestores das concessionárias de serviços públicos não é 
um desafio trivial. Num ambiente em formação, portanto incerto, tal atuação reveste-se de maior complexidade. Fatores políticos (institucionais/regulatórios) guardam, nesse caso, um relacionamento íntimo com os fatores econômicos. É fato que, passados mais de oito anos da privatização das distribuidoras de gás canalizado do Rio de Janeiro, o ambiente regulatório não está totalmente estruturado.

Entre os fatores macroambientais capazes de criar ou deteriorar a vantagem competitiva das firmas, os fatores políticos são de grande importância em indústrias que passaram por processos de reorganização a partir de mudanças estruturais. Os movimentos de desregulamentação e de aumento de pressões sociais e ambientais têm provocado significativas transformações em várias indústrias como as de energia, telecomunicações e transporte aéreo. Usualmente, os gestores de empresas nessa situação não têm dado atenção significativa a tais pressões no nível estratégico.

Em indústrias reguladas, como a de transporte aéreo, de telecomunicações e de utilities, são as políticas públicas que definem a arena competitiva (Bailey, 1997). Apesar disso, são muitas as empresas que não consideram as implicações das variáveis do macroambiente político como parte do processo de análise e formulação de suas estratégias. Mudanças políticas podem criar oportunidades e ameaças, por isso inúmeras indagações surgem nas empresas, quanto à postura estratégica que permita exercer influência na agenda das instituições executivas, legislativas e regulatórias. Há uma integração das tendências políticas com a busca por uma vantagem dinâmica, o que é mais relevante em contextos de redução da regulação econômica e de aumento da regulação social e do meio ambiente (Bailey, 1997).

Esse é um momento particularmente importante para o setor de gás no Brasil. Tramitam no Congresso Nacional três projetos de lei que procuram estabelecer um avanço no marco regulatório do setor: PL no 226/05, PL no 6.666/ 06 e PL no 6.673/06. Até então o gás natural era considerado um apêndice da indústria do petróleo, que teve seu marco estabelecido com a Lei Federal no 9.478/97, a chamada "Lei do Petróleo".

Outro fator de destaque na indústria de óleo e gás brasileira é que, a despeito da tão aclamada e recente auto-suficiência do petróleo, o país continua dependente do suprimento de gás natural da Bolívia, portanto à mercê de pressões político-ideológicas, dentro de uma tradição latino-americana. Instrumentos legais estabelecidos não são necessariamente garantias de um ambiente menos incerto no que se refere à confiabilidade de fornecimento e à estabilidade e à previsibilidade de preços.

Nesse contexto, modelos de estratégia tradicionais, tipicamente estáticos e formais, cercam-se de limitações. Em face de um macroambiente turbu- 
lento e complexo, as empresas necessitam, de forma crescente, estabelecer alianças que maximizem as oportunidades, e minimizem as ameaças geradas por fatores componentes de tal macroambiente e pelos atores estratégicos com os quais interagem. Então, o problema que se coloca neste artigo é: quais são os implicações das alianças e redes de relacionamento mais significativas para a administração de empresas concessionárias de serviços públicos, de distribuição de gás canalizado - a Companhia Distribuidora de Gás do Rio de Janeiro (CEG) e a CEG RIO S.A., de modo a minimizar as ameaças e potencializar as oportunidades de um ambiente que influencia de forma muito intensa essa administração e o conseqüente desempenho empresarial?

Este artigo está estruturado em cinco partes. Na primeira, apresenta-se o referencial teórico da pesquisa. Na segunda, explica-se a sua metodologia. Na terceira, descrevem-se os resultados obtidos da avaliação da adequação da estratégia atual das empresas sob estudo, limitando-se à ótica relacional. $\mathrm{Na}$ quarta, esses resultados são discutidos com vistas a recomendações quanto à melhor adequação da estratégia das empresas. Na última parte, apresentamse a conclusão e as recomendações para futuras pesquisas.

\section{Referencial teórico}

Estratégia é um tema unificador que dá coerência e direção às ações e decisões de uma organização (Grant, 1998), de forma a alavancar e alocar os recursos/ competências necessários para melhorar e sustentar a performance (MacedoSoares, 2000). O ciclo da formulação à realização da estratégia, tendo como resultado a performance empresarial, remete ao conceito de strategic fit ou adequação estratégica (Hofer e Schendel, 1978; Grant, 1998). Estar em conformidade com esse conceito significa que todos os fatores que afetam a estratégia, tanto internos ou organizacionais, quanto externos ou contextuais (macroambientais e atores estratégicos), devem guardar uma consistência entre intenção e realização. Os fatores internos dizem respeito aos recursos/competências da organização que, neste artigo, são um conjunto complexo de habilidades e conhecimentos, exercitados por meio de processos organizacionais que permitem que uma empresa coordene atividades, utilize seus ativos e, continuamente, aprenda e se aperfeiçoe (Day, Reibstein e Gunther, 1997).

Para avaliar as implicações estratégicas dos atores estratégicos foram utilizados os construtos de Porter (1980) e Bradenburger e Nalebuff (1997). No caso dos fatores macroambientais, usaram-se os construtos de Austin (1990). Note-se que Austin elegeu o governo como uma megaforça porquanto, pelo seu controle sobre os recursos e seu poder regulador, tem efeito modulador 
das outras forças exercidas pelos atores estratégicos ao desempenhar seus papéis respectivos.

Para a caracterização da estratégia, explícita ou não, foram utilizados os construtos de Fahey e Randall (1998), com sua proposição de que o conteúdo de qualquer estratégia de uma organização deve confrontar e resolver três conjuntos de escolhas elementares: escopo estratégico; diferenciação competitiva ou postura; e metas. O conteúdo estratégico é conseqüência do processo de elaboração, análise e acompanhamento da estratégia sendo, portanto, uma dimensão intrínseca à sua caracterização. O escopo estratégico subdivide-se em: produto/ serviço, cliente, geografia, grau de verticalização e stakeholders (partes interessadas). A postura é a forma com a qual uma organização diferencia-se de seus atuais e futuros rivais, aos olhos de seus clientes e demais stakeholders (Fahey e Randall, 1998). Metas (goals) compreendem a visão, a missão, os objetivos (intenções), os valores e as metas (físicas e financeiras) propriamente ditas. Na classificação da postura estratégica, optou-se por utilizar a tipologia de estratégias genéricas de diferenciação proposta por Mintzberg (1988): por qualidade; por design; por suporte; por imagem; por tarifa/preço; e não-diferenciação.

Como pressuposto do estudo, considerou-se que os fatores macroambientais, particularmente aqueles relacionados às políticas do setor público, podem criar ou dilapidar vantagens competitivas das empresas, assim como as empresas podem influenciar novas iniciativas políticas. Há, portanto, uma inter-relação entre as mudanças políticas e os recursos/competências da firma, de um lado, e a arena competitiva da indústria, do outro lado (Bailey, 1997).

Duas tendências no comportamento das políticas públicas devem ser destacadas. A primeira, diz respeito ao movimento de reforma regulatória econômica, incluindo desregulamentação e privatização (Bailey, 1997). "A regulação, originalmente, veio para substituir o mercado em determinadas funções e para produzir os efeitos que ele, em determinadas circunstâncias, ao funcionar livremente, não seria capaz de alcançar" (Possas, 2002:59). No entanto, a despeito do movimento de desregulamentação, a regulação tornou-se, com o tempo, ainda mais detalhada e simples questões regulatórias podem levar anos para ser decididas (Bailey, 1997). A segunda tendência consistiu em movimento de incremento no ativismo social e ambiental, o que implicou nova e importante legislação com o objetivo de melhorar a qualidade de vida dos cidadãos (Bailey, 1997). Ambas as tendências, ainda que aparentando caminhar em sentidos contrários, buscaram satisfazer as necessidades dos stakeholders dos seus respectivos setores econômicos.

A base das reformas nos setores de concessões públicas foi a teoria da contestabilidade (Baumol, Panzar e Willing, 1982), que sustenta que monopo- 
listas não precisam ser expostos à competição real para agir de forma competitiva, por estarem sujeitos à ameaça de competição. Já monopólios naturais, "constituem o caso especial em que a concorrência não é preferível à intervenção pública" (Possas, 2002:59). Em atividades em monopólio natural, como a distribuição de gás canalizado, a competição resta pelos possíveis substitutos energéticos. Bailey (1997) alertou para a falta de conhecimento da teoria da contestabilidade por parte dos gestores, que, embora fosse essa a base do seu ambiente competitivo, falhavam em incorporá-la ao seu processo de formulação estratégica.

A indústria e o público em geral, consumidores inclusos, permanentemente interagem com os legisladores e os órgãos executivos e regulatórios, cada qual defendendo seus pontos de vista de forma dinâmica, tentando influenciar uns aos outros. Padrões empíricos que freqüentemente aparecem de questões surgidas das políticas públicas refletem "janelas políticas" (Bailey, 1997). Nessas "janelas" surgem as oportunidades para a ação dos diversos agentes interessados, entre eles os gestores das empresas. Portanto, é necessário que a formulação estratégica dos negócios seja brindada com a dimensão política (Bailey, 1997).

Bailey (1997) sugeriu quatro estratégias para “janelas políticas”, combinando duas dimensões: o grau de regulação - incremento e retirada de restrições regulatórias - e o incentivo prescritivo - iniciativas conjuntas ou à parte de seus competidores. Da combinação dessas dimensões surgiram quatro estratégias genéricas, adotadas neste estudo:

v busca de vantagem relativa diante dos demais agentes da indústria em função das oportunidades do macroambiente;

v busca de vantagem coletiva ante as oportunidades do macroambiente;

- busca de mitigação de desvantagem relativa diante dos demais agentes da indústria em face das ameaças do macroambiente;

busca de mitigação de desvantagem coletiva diante das ameaças do macroambiente.

No tocante ao conceito de alianças, baseou-se em Gulati (1998), que as define como arranjos voluntários entre empresas envolvendo troca, compartilhamento ou co-desenvolvimento de produtos, tecnologias ou serviços. Podem ocorrer como resultado de uma larga gama de motivos e metas, tomar uma variedade de formas e ocorrer transpassando fronteiras verticais e horizontais. São estratégicas quando contribuem diretamente para a vantagem competitiva da empresa (Macedo-Soares, 2002). 
Redes, por sua vez, são construções sociais que surgem de transações contínuas e atividades conjuntas entre participantes num sistema social, definidas como uma pluralidade de atores interagindo com base num sistema de símbolos compartilhados. Os atores participantes de uma rede podem ser designados em vários níveis de análise: indivíduos, pequenos grupos, organizações, coalizões ou nações (Knoke, 2001). Redes serão estratégicas quando forem compostas de laços interorganizacionais duradouros, de significado estratégico (Gulati, Nohria e Zaheer, 2000).

Foi adotada como referência a classificação de Macedo-Soares e Tauhata (2002) para alianças estratégicas, baseada em Contractor e Lorange (1988), Parise (2000) e Nohria e Garcia-Pont (1991), e realizaram-se as modificações requeridas com o intuito de representar as relações e intensidades pertinentes à distribuição de gás canalizado. $\mathrm{O}$ quadro 1 apresenta os tipos de alianças adotados.

\section{Quadro 1}

Descrição dos tipos de alianças estratégicas em função do grau de intensidade para distribuidoras de gás canalizado

\begin{tabular}{ll}
\hline № & Tipo \\
\hline 1 & Fusão/aquisição \\
2 & Joint-venture \\
3 & Participação acionária cruzada \\
4 & Investimento acionário \\
& minoritário \\
5 & Contrato de concessão
\end{tabular}

6 Contrato de fornecimento de gás

7 P\&D em conjunto

8 Desenvolvimento/co-produção

9 Comercialização/marketing em conjunto

\section{Descrição}

Um parceiro adquire uma participação no controle acionário de outro, ou adquire completamente o outro parceiro.

Entidade independente é criada pelos parceiros, com propósito específico. Cada parceiro adquire uma participação acionária no outro parceiro. Um parceiro adquire uma participação acionária minoritária no outro parceiro.

Um parceiro, detentor dos diretos legais sobre determinada atividade econômica, concede a outro parceiro a sua exploração com prazo e condições preestabelecidos.

Um ou mais participantes supre de gás outro participante que, por sua vez, o distribui.

Parceiros concordam em pesquisar e desenvolver produtos/serviços e/ou processos em conjunto. Isso vale para tecnologias de segurança, prevenção de perdas, eficientização do consumo etc.

Parceiros concordam em desenvolver ou produzir produtos e/ou serviços em conjunto.

Parceiros concordam em promover ou comercializar produtos e/ou serviços em conjunto. 


\begin{tabular}{|c|c|c|}
\hline № & Tipo & Descrição \\
\hline 10 & $\begin{array}{l}\text { Licenciamento de patente } \\
\text { ou know-how }\end{array}$ & $\begin{array}{l}\text { Uma empresa que possui tecnologia ou know-how permite a outra } \\
\text { utilizá-lo em troca de uma taxa up-front, seguida por royalties. }\end{array}$ \\
\hline 11 & Transferência de tecnologia & $\begin{array}{l}\text { Arranjo informal no qual parceiros compartilham tecnologia. Pode } \\
\text { ser acompanhado por acordos formais como pactos de } \\
\text { licenciamento ou P\&D. Por exemplo: no caso de empresas } \\
\text { globais que possuam ativos locais, ou seja, entre empresas do } \\
\text { mesmo grupo. }\end{array}$ \\
\hline 12 & Acordo/contrato de P\&D & $\begin{array}{l}\text { Parceiros concordam em pesquisar e desenvolver produtos/serviços } \\
\text { e/ou processos. }\end{array}$ \\
\hline 13 & $\begin{array}{l}\text { Acordo/contrato de fornecimento } \\
\text { de outros insumos e materiais }\end{array}$ & $\begin{array}{l}\text { Um ou mais participantes supre material(is) a outro participante que, } \\
\text { por sua vez, usa esse(s) material(is) para elaborar um produto } \\
\text { acabado e/ou serviço. Por exemplo: ativos da atividade principal } \\
\text { de distribuição. }\end{array}$ \\
\hline 14 & Acordo/contrato de distribuiç̧ão & $\begin{array}{l}\text { Um parceiro distribui o produto e/ou serviço de outro parceiro, } \\
\text { usando sua rede de distribuição. }\end{array}$ \\
\hline 15 & $\begin{array}{l}\text { Acordo/contrato de } \\
\text { comercialização }\end{array}$ & $\begin{array}{l}\text { Um parceiro comercializa o produto e/ou serviço de outro parceiro, } \\
\text { usando sua própria marca. Por exemplo: serviços técnicos } \\
\text { (manutenção corretiva e preventiva) ou comerciais. }\end{array}$ \\
\hline 16 & $\begin{array}{l}\text { Acordo/contrato de prestação } \\
\text { de serviços }\end{array}$ & $\begin{array}{l}\text { Um parceiro presta serviço a outro parceiro ou à aliança, na forma de } \\
\text { assessoria, consultoria, treinamento, assistência técnica etc. Por } \\
\text { exemplo: os órgãos de representação, setoriais e de classe. }\end{array}$ \\
\hline 17 & $\begin{array}{l}\text { Acordo/contrato de fornecimento } \\
\text { de gás spot ou de curto prazo }\end{array}$ & $\begin{array}{l}\text { Um ou mais participantes supre de gás outro participante que, } \\
\text { por sua vez, o distribui, regularizando demanda de curto prazo, } \\
\text { a descoberto dos contratos de fornecimento de longo prazo. }\end{array}$ \\
\hline 18 & $\begin{array}{l}\text { Acordo/contrato de financiamento } \\
\text { spot ou de curto prazo }\end{array}$ & $\begin{array}{l}\text { Um ou mais participantes supre recursos financeiros a outro } \\
\text { participante que, por sua vez, usa-os para elaborar um produto } \\
\text { acabado e/ou serviço em curto prazo (igual ou inferior a um ano). }\end{array}$ \\
\hline
\end{tabular}

Fonte: Adaptado de Macedo-Soares e Tauhata (2002).

Obs.: Foram colocadas em negrito as contribuições relativas ao setor de gás canalizado.

Na perspectiva relacional, enxerga-se a configuração - externa e interna - das organizações por meio de seus relacionamentos que são, por sua vez, fontes de vantagem competitiva. Essa visão remete à rede de valor (value map) de Bradenburger e Nalebuff (1997): um mapa constituído pelo conjunto de jogadores no jogo dos negócios, incluindo-se o que eles chamaram de complementors, assim como suas interdependências, ou seja, todos os elementos que contribuem à captura ou criação de valor requerido para a vantagem competitiva da empresa focal. 
A análise relacional proposta neste artigo usou o modelo strategic network analysis (SNA) (Macedo-Soares, 2002), para o caso de empresas que atuam em alianças e redes. Trata-se de uma evolução do modelo genérico integrativo (GI) (Macedo-Soares, 2000), construído a partir de uma série de arcabouços anteriores (Macedo-Soares e Chamone, 1994; Macedo-Soares e Lucas, 1996), inspirados, inicialmente, na escola sociotécnica (Cherns, 1976) e que incorporou, posteriormente, alguns construtos de Austin (1990), de Porter (1980) e da visão baseada em recursos (Wernerfelt, 1984). O modelo GI possibilita analisar as variáveis críticas internas à empresa, em interação com as externas mais relevantes, para avaliar sua adequação estratégica na ótica tradicional, ou seja, sem contemplar relacionamentos, tipo de alianças e as redes formadas por estas. O modelo SNA preserva as características genérico-integrativas do modelo GI, ampliando-as para uma perspectiva relacional.

No modelo SNA, alinhado ao conceito de rede de valor de Bradenburger e Nalebuff (1997), o que está em evidência é a rede formada a partir de uma empresa focal, permitindo mapear as alianças e as características dos relacionamentos da ego-rede da empresa focal. Esse conceito foi adaptado do conceito de rede egocêntrica de Knoke (2001), em que se representam apenas os laços diretos de cada ator. As ligações entre os atores estratégicos se dão por meio de alianças de diferentes tipos e a caracterização dos laços entre os parceiros leva ao entendimento da empresa focal e sua participação numa rede mais ampla (rede de valor).

Dessa forma, a análise estratégica das empresas estudadas envolveu os seguintes passos:

- caracterização da estratégia corrente explícita ou implícita da(s) empresa(s);

v identificação dos fatores ambientais e dos atores estratégicos-chave da rede de valor da(s) empresa(s) e avaliação de suas implicações estratégicas no sentido de constituírem oportunidades e ameaças, reais e potenciais;

v identificação dos fatores organizacionais da(s) empresas e de suas implicações estratégicas, no sentido de constituírem forças e fraquezas, reais e potenciais;

- identificação e classificação das alianças estratégicas e laços significativos entre os participantes das redes de valor da(s) empresa(s);

- identificação das características relacionais da ego-rede da(s) empresa(s);

v avaliação do desempenho da(s) empresa(s);

v avaliação da adequação estratégica da(s) empresa(s);

- sugestão, com base nos resultados da avaliação estratégica, de ajustes na estratégia da(s) empresa(s). 
Não se pretendeu aprofundar as implicações estratégicas das forças e fraquezas das empresas em estudo. No entanto, essas implicações não puderam ser deixadas de lado, sob pena de empobrecer a avaliação da adequação estratégica considerando as oportunidades e ameaças do macroambiente. Assim, foram utilizados construtos simplificados do modelo GI, Macedo-Soares (2000), Coutinho e Macedo-Soares (2002) e Macedo-Soares e Figueira (2004), e adaptados para o setor de distribuição de gás canalizado.

Uma coletânea de construtos utilizados para operacionalizar a análise estratégica relacional foi apresentada por Macedo-Soares (2002) e Tahuata (2002), baseando-se em diversos trabalhos dos quais se destacam Galaskiewicz e Zaheer (1999), Gulati, Nohria e Zaheer (2000), Kale, Singh e Perlmutter (2000) e Knocke (2001). Tais construtos foram adaptados para o setor de distribuição de gás canalizado, para o nível corporativo da empresa focal e para a indústria na qual ela se insere, em três categorias de construtos relacionais no nível da indústria e da empresa, além de um quarto construto no nível da empresa (quadro 2).

\begin{tabular}{|c|c|c|}
\hline \multicolumn{3}{|c|}{$\begin{array}{l}\text { Quadro } 2 \\
\text { Construtos para análise estratégica relacional }\end{array}$} \\
\hline Categoria & Descrição & Construtos associados \\
\hline Estrutura da rede & $\begin{array}{l}\text { Compreende o padrão dos } \\
\text { relacionamentos no qual a empresa } \\
\text { focal ou a indústria focal estão inseridas. }\end{array}$ & $\begin{array}{l}\text { Densidade, escopo, posição e centralidade, } \\
\text { orifícios estruturais, tipo de laço, equivalência } \\
\text { estrutural e padrão dos laços. }\end{array}$ \\
\hline $\begin{array}{l}\text { Composição } \\
\text { da rede }\end{array}$ & $\begin{array}{l}\text { Expressa as características dos } \\
\text { membros da rede, ou seja, dos } \\
\text { atores da rede de valor da empresa } \\
\text { focal ou da indústria focal. }\end{array}$ & $\begin{array}{l}\text { Identidade, status e acesso aos recursos da } \\
\text { empresa focal e da indústria focal. }\end{array}$ \\
\hline $\begin{array}{l}\text { Modalidade } \\
\text { da rede }\end{array}$ & $\begin{array}{l}\text { É o conjunto de regras e normas } \\
\text { institucionalizadas que direcionam } \\
0 \text { comportamento apropriado dos } \\
\text { atores na rede. }\end{array}$ & Força das conexões e natureza dos laços. \\
\hline $\begin{array}{l}\text { Gerenciamento } \\
\text { da rede }\end{array}$ & $\begin{array}{l}\text { Diz respeito aos fatores sob os quais } \\
\text { a rede é administrada. }\end{array}$ & $\begin{array}{l}\text { Uso de mecanismos de governança, rotinas de } \\
\text { compartilhamento de informações interfirmas, } \\
\text { investimentos em relacionamentos específicos, } \\
\text { desenvolvimento de processos de gestão da } \\
\text { mudança no âmbito da rede, experiência em } \\
\text { múltiplas alianças, e processos e competências } \\
\text { para a gestão da adequação dinâmica dos } \\
\text { múltiplos parceiros. }\end{array}$ \\
\hline
\end{tabular}




\section{Metodologia}

Conduziu-se um estudo de caso, método adequado segundo Yin (1994), quando envolve um fenômeno contemporâneo - conduta estratégica corrente da CEG e da CEG RIO e seu conseqüente desempenho - dentro de seu contexto real, especialmente quando as fronteiras entre o fenômeno e seu contexto - o macroambiente - não são claramente estabelecidas. Ainda conforme Yin (1994), foram utilizadas múltiplas fontes de evidência: investigação documental/telematizada e levantamento de percepções por meio de questionário predominantemente estruturado e de entrevistas com roteiro, numa triangulação que permitiu a convergência dos dados.

O estudo cobriu as duas distribuidoras de gás canalizado do estado do Rio de Janeiro (CEG e CEG RIO) no período de 1998 a 2005. Embora sejam duas concessões distintas, com naturezas jurídicas próprias e composições acionárias diferentes, o controlador e operador técnico são os mesmos e há um total alinhamento estratégico e operacional entre as empresas. De fato, atuam como uma única empresa. A CEG RIO não possui qualquer estrutura administrativa, sendo todos os processos de negócios (fins e de suporte) operados pela estrutura da CEG. Por esses serviços a CEG RIO remunera a CEG. Embora tenham sido enfocadas duas empresas (CEG e CEG RIO), pode ser considerado um estudo de caso simples, tal sua integração administrativa.

A pesquisa de campo se desenvolveu em duas etapas. A primeira, tipo survey, compreendeu a aplicação de um questionário estruturado para identificar as percepções dos funcionários das empresas nos seguintes temas: caracterização da estratégia; validação das implicações estratégicas dos fatores organizacionais; validação das implicações estratégicas dos fatores macroambientais; e validação das implicações estratégicas das alianças e redes. Procurou-se avaliar a relevância da contribuição potencial de cada funcionário da CEG ao estudo, restringindo-se o grupo que respondeu ao questionário ao número mínimo indispensável. Na segunda etapa, foi feito um levantamento complementar com a realização de entrevistas individuais com um grupo de executivos das empresas.

A taxa de resposta ao questionário foi calculada a partir da fórmula de Rea e Parker (2000) para determinação do tamanho da amostra para populações pequenas. Admitiu-se para fins deste estudo, simplificadamente, que a população era homogênea, em termos de percepção, não existindo disparidades nem em função da área a que cada pessoa pertencia, nem em função de seu nível hierárquico. Com isso, chegou-se a um número mínimo de 19 respondentes sobre o total de 54 questionários distribuídos. Com taxa de resposta de 48\% (26 respondentes), o intervalo de confiança e o erro máximo desejados foram atingidos. 
O estudo possuiu a limitação de não permitir a generalização para outras empresas do setor - no caso da presente pesquisa, o setor de distribuição de gás canalizado no Brasil - ou para outros setores de negócios como, por exemplo, outras concessões de serviços públicos. Quanto à coleta e ao tratamento dos dados, também houve algumas limitações decorrentes dos métodos. No entanto, a triangulação dos métodos, com a utilização de vários instrumentos para coleta de dados, permitiu superar grande parte das limitações de cada método individual utilizado.

\section{Resultados}

\section{Contextualização}

Em 1997, o estado do Rio de Janeiro, no âmbito do Programa Estadual de Desestatização, privatizou a Companhia Estadual de Gás do Rio de Janeiro (CEG) e a Riogás S.A. (Riogás), através da alienação de 65,41\% das ações ordinárias da CEG e 83,67\% das ações ordinárias mais 70,66\% das ações preferenciais da Riogás perfazendo um total de $75 \%$ do capital desta última empresa. A Riogás foi criada em janeiro de 1997, com o objetivo de distribuir gás canalizado a 65 municípios do interior do estado do Rio de Janeiro. Portanto, quando privatizada era uma empresa praticamente sem operação, tendo nascido com a incorporação de alguns ativos de distribuição já existentes e oito clientes da Petrobras. Os controles acionários da CEG e da Riogás foram vendidos no mesmo leilão de privatização. Desde então, as composições acionárias sofreram alterações até chegar às atuais em que o grupo Gas Natural, de capital espanhol, passou a ser não só o sócio operador, como também o controlador das empresas. Atualmente, as empresas possuem as razões sociais de Companhia Distribuidora de Gás do Rio de Janeiro (CEG) e CEG RIO S.A., respectivamente.

Os contratos de concessão da CEG e da CEG RIO foram assinados em 21 de julho de 1997. No caso da CEG, foi exigida a total conversão do gás manufaturado para o gás natural, sendo previsto, originalmente, o prazo de 90 meses para que toda a cidade do Rio de Janeiro estivesse atendida pelo gás natural. No caso da CEG RIO, o gás distribuído sempre foi o natural. Logo após a privatização, a CEG iniciou o projeto de conversão. Para garantia de total segurança nessa operação, houve necessidade de revisão prévia completa das instalações e nos aparelhos a gás, após o que fogões, fornos, aquecedores e boilers foram adaptados para receber o novo gás. Incidentes ocorridos em seu início fizeram com que o projeto de conversão sofresse interrupções e atrasos, postergando seu término para meados de 2007, segundo a CEG. 
O projeto de conversão foi uma fonte de desgaste da CEG junto ao órgão regulador, o poder concedente, os clientes e a opinião pública de uma forma geral. Segundo a empresa, os problemas existentes nos primeiros anos de conversão deveram-se à inexistência de cultura de gás pelos consumidores. Isso parecia conflitante com uma história de mais de 150 anos de existência da empresa e do consumo de gás na cidade do Rio de Janeiro, mas o entendimento da empresa era de que havia um total desconhecimento por parte dos consumidores em relação às normas de segurança, o que levava a um estado bastante ruim de conservação dos equipamentos movidos a gás, razão principal para as dificuldades no processo de conversão. É fato reconhecido pela CEG que havia falta de mão-de-obra especializada para os serviços de conversão, e que toda a experiência prévia do grupo Gas Natural em outras partes do mundo não foi suficiente para lidar no curto prazo com essa carência. O desgaste da imagem da empresa precisou ser revertido por um amplo processo de comunicação e pela melhoria no processo de conversão.

$\mathrm{Na}$ indústria do gás natural no Brasil as atividades de produção, importação, transporte e comercialização estão sob a regulação da Agência Nacional de Petróleo, Gás Natural e Biocombustíveis (ANP). A atividade de distribuição encontra-se sob a regulação de agências estaduais. Algumas das interações entre os agentes da indústria são puramente comerciais, enquanto outras envolvem o fluxo do gás.

O transporte é feito por gasodutos, pode envolver etapas de compressão até a forma criogênica (gás natural liquefeito) e diz respeito a grandes volumes, dos locais de produção até os city-gates. ${ }^{1}$ Já a atividade de distribuição faz chegar o gás aos consumidores finais, por uma rede de distribuição de alta, média e baixa pressões. Em muitos países, a atividade de distribuição é segmentada entre a distribuição propriamente dita e a comercialização. Nessa última dá-se a transação comercial e todo o contato com os clientes. O comercializador não possui ativos de distribuição, mas os usa, e para tal os clientes pagam uma tarifa de distribuição. No Brasil, hoje não existe tal distinção e a atividade de distribuição de gás canalizado engloba a comercialização. A atividade de distribuição de gás canalizado tipicamente envolve monopólio natural, já que não há viabilidade econômica de mais de uma rede de dutos numa mesma área geográfica.

Os dispositivos da Constituição da República já mencionados provocaram alterações nas Constituições estaduais. Na do Rio de Janeiro, promulgada em 5 de outubro de 1989, há diversas determinações relativas ao gás canalizado. Destaque-se o art. 229 em que o direito ao acesso ao gás canalizado é

\footnotetext{
1 "Portas de entrada" na rede de distribuição, a partir do transporte do gás pelos gasodutos.
} 
considerado função social para garantir a qualidade de vida da população, perfilado com direitos como saúde e educação. Já o art. 246 estabelece a prioridade de distribuição no próprio estado do Rio de Janeiro do gás produzido no estado evidenciando a importância dada a esse energético.

Como conseqüência dos dispositivos constitucionais, foi estabelecida legislação a amparar o processo de desestatização que culminou na celebração de contratos de concessão entre o poder concedente e os novos controladores das empresas permissionárias de serviços públicos. O acompanhamento cronológico dos dispositivos legais do setor de distribuição de gás canalizado demonstra que o marco regulatório do setor não estava estabelecido previamente à privatização e à conseqüente celebração dos contratos de concessão da CEG e da CEG RIO. À Agência Reguladora de Energia e Saneamento Básico do Estado do Rio de Janeiro (Agenersa), anteriormente Agência Reguladora de Serviços Públicos do Estado do Rio de Janeiro (Asep-RJ), foi atribuída a fiscalização dos contratos de concessão, entre outras atribuições regulatórias.

Os contratos de concessão das empresas têm sido alvos constantes, até os dias de hoje, de questionamentos e discussões entre as partes. Dois temas críticos recorrentes, com efeito direto na administração das empresas, foram reiteradamente debatidos: o nível de investimentos, para expansão e melhoria de qualidade dos serviços, e as tarifas, abrangendo sua estrutura e a metodologia de revisões.

No período analisado, de 1998 a 2005, o mercado da CEG e da CEG RIO sofreu profundas mudanças. No quadro 3 são relacionados alguns fatos de destaque no desempenho das empresas.

\begin{tabular}{|c|c|}
\hline \multicolumn{2}{|r|}{$\begin{array}{c}\text { Quadro } 3 \\
\text { Fatos de destaque no desempenho da CEG e da CEG RIO } \\
\text { de } 1998 \text { a } 2005\end{array}$} \\
\hline Empresa & Fatos de destaque no desempenho \\
\hline CEG & 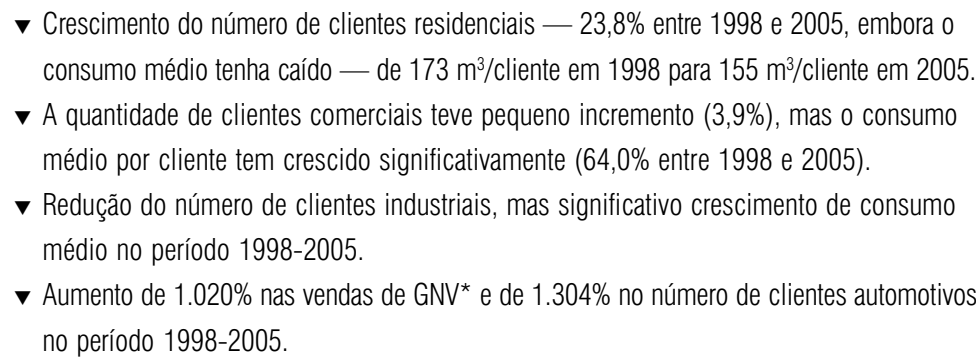 \\
\hline
\end{tabular}




\begin{tabular}{|c|c|}
\hline Empresa & Fatos de destaque no desempenho \\
\hline CEG RIO & 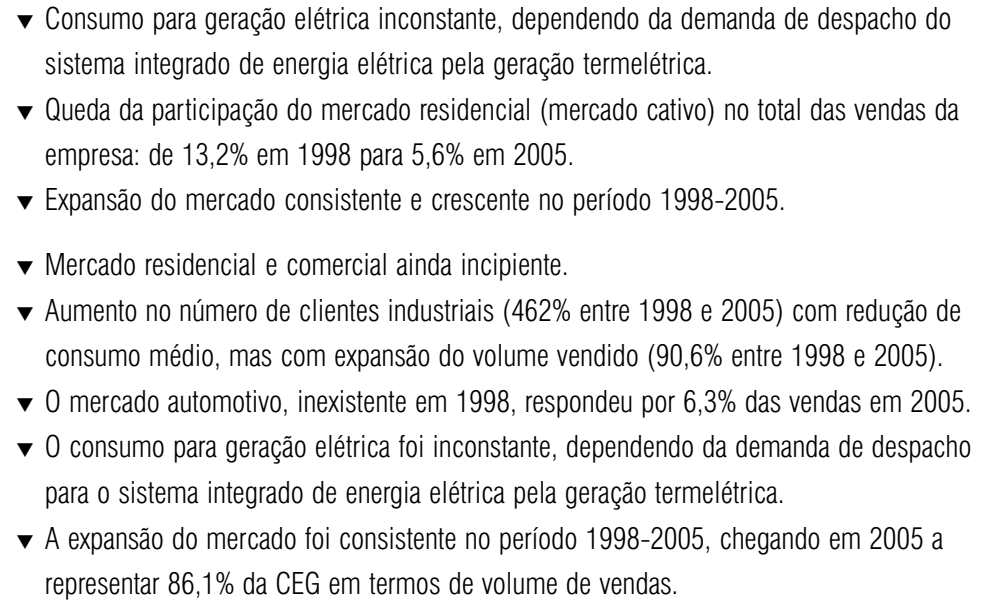 \\
\hline \multicolumn{2}{|c|}{$\begin{array}{l}\text { Fonte: Relatórios anuais das empresas. } \\
\text { * Gás natural veicular. É exatamente o mesmo gás utilizado pelas demais classes de clientes, portanto é apenas um "nome de } \\
\text { batismo". } 0 \text { GNV é vendido com tarifa específica pela Petrobras. }\end{array}$} \\
\hline
\end{tabular}

A rede de gás da CEG cresceu 51,9\% de 1998 a 2005, enquanto a da CEG RIO cresceu 119,7\% no mesmo período. A forte ampliação da rede de distribuição estava alinhada com a estratégia de expansão das empresas, em termos de municípios a serem atendidos. Já a evolução da quantidade de clientes indicava a busca pelo aumento do índice de penetração nas áreas geográficas já com fornecimento de gás, além da captação de novos clientes nas áreas com fornecimento recente de gás.

\section{Caracterização da estratégia}

A missão, a visão e os valores que direcionaram a CEG e a CEG RIO eram os mesmos de sua controladora, o grupo Gas Natural, da Espanha, e estavam expressos publicamente no seu website (portal.gasnatural.com). Nos enunciados da missão e da visão encontraram-se referências a temas como a excelência dos serviços e produtos, o respeito ao meio ambiente, a rentabilidade crescente e sustentável, a posição de liderança como grupo energético, a presença multinacional, a ampliação de oportunidades de desenvolvimento profissional e pessoal aos empregados e a contribuição positiva à sociedade. 
Os valores que guiaram as ações do grupo Gas Natural eram: orientação ao cliente; compromisso com os resultados; sustentabilidade; interesse pelas pessoas; responsabilidade social; e integridade. Adicionalmente, foram estabelecidos princípios de atuação para quatro grupos de interesse (stakeholders): clientes, acionistas, empregados e sociedade. Cabe o destaque de que não foi feita menção ao poder concedente e aos órgãos reguladores como grupos de interesse. Possivelmente porque, do ponto de vista do grupo Gas Natural e do mercado espanhol, não existisse uma problemática relevante quanto a esses stakeholders.

A investigação documental realizada confirmou que o grupo Gas Natural tinha o objetivo de se firmar como uma empresa multinacional do setor de energia, consolidando suas posições na América Latina e ampliando sua presença no mercado brasileiro - crescente - em função de seu grande potencial para fornecimento de gás, do desenvolvimento do gás natural veicular e da expansão das térmicas. A CEG e a CEG RIO tinham como objetivos principais:

v a ampliação do número de clientes, exigindo investimentos na expansão da rede de gasodutos, rumo à universalização dos serviços de distribuição de gás canalizado na área de concessão;

จ a busca de eficiência e redução de custos;

จ a viabilização de parte dos recursos para investimentos das tarifas;

v a conclusão da conversão do gás manufaturado para o gás natural;

a busca da excelência no atendimento aos clientes, ancorada na segurança e na confiabilidade do fornecimento de gás.

A caracterização do escopo estratégico, que obedeceu às categorias e construtos de Fahey e Randall (1998), apontou para os seguintes resultados:

> produtos - gases manufaturado, natural e GLP distribuídos de forma canalizada;

> tipos de consumidores/clientes - residenciais, comerciais, industriais, geração e co-geração de energia, veículos e termelétricas (mercado nãoconvencional);

、 municípios na área de concessão da CEG - Rio de Janeiro, Belford Roxo, Duque de Caxias, Guapimirim, Itaboraí, Itaguaí, Japeri, Magé, Mangaratiba, Maricá, Nilópolis, Niterói, Nova Iguaçu, Paracambi, Queimados, São Gonçalo, Tanguá, Seropédica e São João de Meriti; 
v área de concessão da CEG RIO - norte e noroeste fluminenses, baixada litorânea, médio Paraíba, Região Serrana, centro-sul e baía da Ilha Grande;

v stakeholders - sociedade, clientes, acionistas e empregados. Destaque-se a inexistência de menção explícita ao poder concedente (estado do Rio de Janeiro) e aos órgãos reguladores (Agenersa e ANP);

$\checkmark$ processo de planejamento estratégico - centralizado e restrito a um pequeno grupo de executivos na formulação das diretrizes, objetivos, metas e premissas, fortemente influenciado e limitado ao referencial estabelecido no planejamento estratégico do grupo Gas Natural.

A postura estratégica das empresas era ancorada em três pontos: crescimento (expansão da rede e da base de clientes), rentabilidade e qualidade. $\mathrm{O}$ levantamento de percepções apontou a estratégia de diferenciação pela qualidade orientada ao cliente como aquela adotada pelas empresas $(73,1 \%$ das respostas), embora houvesse menções à diferenciação por suporte $(11,5 \%)$ e por tarifa/preço $(15,4 \%)$.

Não pôde ser confirmada a postura estratégica quanto ao tratamento das incertezas do macroambiente, conforme tipologia de Bailey (1997). Dos respondentes ao questionário de percepções, 70,8\% entendiam que as obrigações regulatórias econômicas tenderiam a crescer nos próximos cinco anos, enquanto $100 \%$ dos respondentes acreditavam na mesma tendência quanto às obrigações regulatórias sociais e ambientais. Entretanto, não houve evidências de um direcionamento ante o ambiente regulatório. Constatou-se um relacionamento formal e reativo com o regulador, não sendo identificada uma postura proativa de natureza negociadora em prol da evolução do marco regulatório.

As empresas vinham atuando pelos órgãos de representação, principalmente da Abegás, nos assuntos regulatórios no âmbito regional e nacional, mas não pôde ser constatada uma intenção estratégica como a apontada na pesquisa de percepções. Quanto à estratégia para o tratamento das incertezas do macroambiente político-institucional, $31,8 \%$ dos pesquisados entendiam que a empresa não elaborava estratégias específicas, atuando caso a caso. Apenas $9,0 \%$ entendiam que a empresa buscava mitigar desvantagens, coletivas ou relativas, diante dos demais agentes da indústria. Já $59,2 \%$ entendiam que a empresa buscava vantagens relativas em relação aos demais agentes da indústria $(41,0 \%)$ e às oportunidades do macroambiente $(18,2 \%)$.

\section{Ego-rede da CEG e da CEG RIO}

No quadro 4 apresentam-se os componentes da ego-rede da CEG e da CEG RIO, a partir dos papéis genéricos de atores componentes da rede de valor de 
uma empresa distribuidora de gás canalizado, apontado os principais atores estratégicos/parceiros e o relacionamento das empresas com eles.

\section{Quadro 4}

\section{Atores estratégicos/parceiros por papel genérico e seus tipos de alianças na ego-rede da CEG e da CEG RIO}

\begin{tabular}{|c|c|c|}
\hline Papel genérico & Atores estratégicos/parceiros & $\begin{array}{l}\text { Tipos de alianças com os atores } \\
\text { estratégicos/parceiros }\end{array}$ \\
\hline Clientes & $\begin{array}{l}\text { Residências, comércio (padarias, restaurantes, } \\
\text { hotéis, escolas de natação, clubes etc.), } \\
\text { indústrias (cerâmicas, fundições, tratamentos } \\
\text { térmicos etc.), geração e co-geração (fábricas, } \\
\text { centros de saúde, hotéis, grandes complexos } \\
\text { urbanísticos etc.), termelétricas e veículos. }\end{array}$ & $\begin{array}{l}\text { Contrato de fornecimento de gás e } \\
\text { acordo/contrato de prestação de } \\
\text { serviços. }\end{array}$ \\
\hline Fornecedores & $\begin{array}{l}\text { Petrobras (gás natural, nafta), fabricantes de } \\
\text { equipamentos de rede (tubulações e acessórios), } \\
\text { serviços de construção e manutenção de rede, } \\
\text { serviços de instalação e manutenção de } \\
\text { equipamentos internos dos clientes, serviços } \\
\text { administrativos (auditoria, consultoria, seguranç̧a, } \\
\text { serviços gerais etc.). }\end{array}$ & $\begin{array}{l}\text { Acordo/contrato de suprimento de } \\
\text { produtos e acordo/contrato de } \\
\text { prestação de serviços. }\end{array}$ \\
\hline Substitutos & $\begin{array}{l}\text { Energéticos substitutos: energia elétrica, gasolina, } \\
\text { álcool, diesel, óleo combustível, GLP (gás } \\
\text { liquefeito de petróleo), GNC (gás natural } \\
\text { comprimido) e GNL (gás natural líquido). }\end{array}$ & Não identificados. \\
\hline Concorrentes & $\begin{array}{l}\text { Distribuidores/comercializadores de energéticos } \\
\text { substitutos (Light, Ampla, Shell, Ipiranga, } \\
\text { Petrobras etc.). }\end{array}$ & Não identificados. \\
\hline Novos entrantes & Não identificados. & Não identificados. \\
\hline Complementors & $\begin{array}{l}\text { Serviços adicionais de projeto e suporte técnico } \\
\text { relacionados, por exemplo, aos distribuidores de } \\
\text { combustíveis (postos de gás natural veicular), aos } \\
\text { fabricantes de equipamentos movidos a gás } \\
\text { (fornos, fogões, aquecedores, lavadoras de roupa, } \\
\text { lavadoras de louça, radiadores murais, lareiras, } \\
\text { churrasqueiras, co-geradores de calor/energia } \\
\text { elétrica, centrais térmicas convencionais e de } \\
\text { ciclo combinado e combustível para veículos } \\
\text { motores) e às construtoras de imóveis com uso } \\
\text { do gás natural canalizado. }\end{array}$ & $\begin{array}{l}\text { Acordos de comercialização/ } \\
\text { marketing em conjunto e acordo/ } \\
\text { contrato de prestação de serviços. }\end{array}$ \\
\hline
\end{tabular}




\begin{tabular}{|lll|}
\hline \multicolumn{1}{|c}{ Papel genérico } & Atores estratégicos/parceiros & $\begin{array}{l}\text { Tipos de alianças com os atores } \\
\text { estratégicos/parceiros }\end{array}$ \\
\hline $\begin{array}{l}\text { Órgãos } \\
\text { governamentais/ } \\
\text { reguladores/ } \\
\text { outros órgãos e }\end{array}$ & $\begin{array}{l}\text { Poder concedente (estado do Rio de Janeiro), } \\
\text { associas reguladoras (Agenersa, ANP, Aneel), }\end{array}$ & $\begin{array}{l}\text { Contrato de concessão e acordos/ } \\
\text { contratos de cooperação. }\end{array}$ \\
& $\begin{array}{l}\text { Secretaria de Estado de Energia, Indústria Naval e } \\
\text { do Petróleo do Estado do Rio de Janeiro), }\end{array}$ & \\
& associações de classe e representação (exemplo: & \\
Empresas com & Abegás). & \\
interesse & Grupo Gas Natural, empresas com participação & Acordos de comercialização/ \\
acionário & societária do grupo Gas Natural (Serviços e GN & marketing em conjunto, acordos/ \\
& São Paulo Sul) e Petrobras. & $\begin{array}{l}\text { contratos de transferência de } \\
\text { tecnologia, acordos/contratos de } \\
\text { prestação de serviços e } \\
\text { participações societárias. }\end{array}$ \\
& &
\end{tabular}

\section{Implicações estratégicas das alianças e redes}

Pôde-se constatar, a partir das respostas ao questionário da survey, uma percepção da importância da participação das empresas em alianças e redes como parte fundamental das estratégias da atividade de distribuição de gás, de foco no cliente e de tratamento de incertezas do macroambiente político-institucional. No entanto, ao se aprofundar o tema nas entrevistas realizadas, ficou evidente uma baixa compreensão do potencial de uso de alianças e redes estratégicas. Elos, muitas vezes obrigatórios, como os contratos de concessão, são fato na relação das concessionárias com os demais atores/parceiros. Mas a natureza estratégica da construção desses elos não foi explicitada.

Os cinco principais fatores motivadores identificados para o estabelecimento de alianças estratégicas na CEG e na CEG RIO, são listados a seguir pela ordem de importância: posicionamento diante das mudanças políticas e institucionais; gerenciamento de incertezas; compartilhamento de custos; acesso ao capital de informações proporcionadas por novos relacionamentos; e estreitamento de relações comerciais. Isso confirma o entendimento preliminar de que as mudanças/incertezas dos fatores macroambientais são muito importantes nesse tipo de indústria e que são os maiores motivadores de possíveis alianças estratégicas. Embora tenha sido respondido que as empresas participam, tipicamente, de alianças tanto bilaterais quanto multilaterais, não foi possível confirmar a existência das últimas. Não existe clareza quanto à centralidade da CEG e da CEG RIO no setor de distribuição de gás 
no Brasil a partir da observação da exposição das empresas na mídia e nos documentos analisados.

Não foi possível identificar orifícios estruturais, tampouco equivalências às redes das empresas. Contudo, havia uma clara percepção de que a formação de alianças ou redes com indústrias e empresas equivalentes agregaria valor aos produtos e serviços oferecidos aos clientes, com impacto positivo em relação à vantagem competitiva, à imagem, à percepção de valor, à fidelização dos clientes e ao desempenho global das empresas. Também era percebido que as alianças traziam efeitos no aumento da capacidade em lidar com fatores políticos, demográficos, culturais e econômicos. No entanto, o mesmo não foi evidenciado quanto ao aumento ou diminuição do poder de barganha dos fornecedores, do poder de barganha dos clientes, da capacidade de evitar substitutos e do grau de rivalidade entre concorrentes.

O maior volume de alianças das empresas se dava com fornecedores de serviços. Foi evidenciada a preocupação em gerir esses relacionamentos com indicadores de qualidade e de capacitação da mão-de-obra terceirizada. Não foi identificada outra forma de gestão de alianças em termos de sistemas de controle a partir de indicadores de desempenho.

Os quadros 5 e 6 resumem o resultado da análise relacional da CEG e da CEG RIO, em termos de implicações estratégicas, nos níveis da empresa e da indústria.

\begin{tabular}{|lll|}
\hline \multicolumn{2}{|c|}{$\begin{array}{c}\text { Quadro } \\
\text { Implicações estratégicas das alianças e redes da CEG e da } \\
\text { CEG RIO no nível da indústria }\end{array}$} \\
\hline Construtos & Indicadores & Implicações estratégicas no nível da indústria \\
\hline Densidade & Alta densidade & $\begin{array}{l}\text { Oportunidade real — existência de grande } \\
\text { quantidade de alianças implicando barreira aos } \\
\text { rivais em segmentos de clientes cujo mercado } \\
\text { não é cativo. }\end{array}$ \\
& $\begin{array}{l}\text { Oportunidade real — a garantia de um mercado } \\
\text { cativo, numa limitação geográfica (área de } \\
\text { concessão), garante remuneração da indústria. } \\
\text { Da mesma forma, o escopo bem definido nos } \\
\text { mercados onde há concorrência, mas sujeito à } \\
\text { regulação, tende a garantir a rentabilidade da } \\
\text { indústria. No entanto, há uma limitação máxima } \\
\text { de mercado. }\end{array}$ \\
\hline
\end{tabular}




\begin{tabular}{|c|c|c|}
\hline Construtos & Indicadores & Implicações estratégicas no nível da indústria \\
\hline \multirow[t]{4}{*}{$\begin{array}{l}\text { Posição e } \\
\text { centralidade }\end{array}$} & $\begin{array}{l}\text { Central em relação à área de } \\
\text { concessão }\end{array}$ & $\begin{array}{l}\text { Oportunidade real - grande acesso a recursos/ } \\
\text { informações e ao controle sobre as ações de } \\
\text { gestão operacional (técnica e comercial) em } \\
\text { função da alta centralidade na área de } \\
\text { concessão. }\end{array}$ \\
\hline & $\begin{array}{l}\text { Intermediária em relação ao } \\
\text { segmento de gás canalizado no }\end{array}$ & $\begin{array}{l}\text { Oportunidade potencial — por serem concessões } \\
\text { estaduais, há limitações na atuação de cada }\end{array}$ \\
\hline & Brasil & $\begin{array}{l}\text { concessionária de distribuição de gás canalizado } \\
\text { no Brasil, impedindo que haja uma maior } \\
\text { centralidade de umas em relação às demais. } \\
\text { Ainda assim, a posição da CEG e da CEG RIO } \\
\text { pôde ser considerada intermediária, já que, } \\
\text { juntamente com a GN SP Sul, integra um grupo de } \\
\text { ativos sob o controle de um grupo forte. }\end{array}$ \\
\hline & $\begin{array}{l}\text { Periférica em relação à cadeia } \\
\text { total do gás no Brasil }\end{array}$ & $\begin{array}{l}\text { Ameaça potencial — com relação à cadeia do } \\
\text { gás, a centralidade das empresas era baixa, em } \\
\text { função da posição de dominância da Petrobras, } \\
\text { com seus múltiplos papéis e atuação em } \\
\text { segmentos monopolistas. }\end{array}$ \\
\hline Orifícios estruturais & Inexistentes & $\begin{array}{l}\text { Ameaça potencial - não foram identificados } \\
\text { orifícios estruturais que permitissem influenciar } \\
\text { positivamente a rentabilidade da indústria e das } \\
\text { empresas estudadas. }\end{array}$ \\
\hline \multirow[t]{4}{*}{$\begin{array}{l}\text { Identidade dos } \\
\text { parceiros da indústria } \\
\text { focal }\end{array}$} & Forte & $\begin{array}{l}\text { Oportunidade real — a identidade do poder } \\
\text { concedente (estado do Rio de Janeiro) era } \\
\text { forte, o que impactava favoravelmente os } \\
\text { planos de expansão e rentabilidade das } \\
\text { empresas. }\end{array}$ \\
\hline & Forte & $\begin{array}{l}\text { Oportunidade potencial — a identidade forte de } \\
\text { grandes clientes poderia ser mais explorada em } \\
\text { prol da rentabilidade da indústria. }\end{array}$ \\
\hline & Fraca & $\begin{array}{l}\text { Ameaça potencial — os fornecedores tinham } \\
\text { identidade fraca, o que não contribuía para o } \\
\text { aumento de lucratividade da indústria de } \\
\text { distribuição de gás canalizado. }\end{array}$ \\
\hline & Fraca & $\begin{array}{l}\text { Oportunidade potencial — o regulador estadual } \\
\text { (Agenersa) possuía identidade fraca, o que } \\
\text { gerava menores pressões à rentabilidade da } \\
\text { indústria. }\end{array}$ \\
\hline
\end{tabular}




\begin{tabular}{|c|c|c|}
\hline Construtos & Indicadores & Implicações estratégicas no nível da indústria \\
\hline $\begin{array}{l}\text { Status dos parceiros } \\
\text { da indústria focal }\end{array}$ & Sucesso & $\begin{array}{l}\text { Oportunidade real - sucesso dos principais } \\
\text { parceiros no relacionamento com as empresas } \\
\text { no nível da indústria, constituindo oportunidade } \\
\text { real para alavancar a rentabilidade, } 0 \\
\text { crescimento e a influência nos fatores políticos } \\
\text { atuando sobre o setor. }\end{array}$ \\
\hline $\begin{array}{l}\text { Acesso a recursos da } \\
\text { indústria focal }\end{array}$ & Difícil & $\begin{array}{l}\text { Ameaça potencial - embora concessões, cuja } \\
\text { ação regulatória deveria buscar reduzir a } \\
\text { assimetria de informações, na prática isso não } \\
\text { se dava. }\end{array}$ \\
\hline Força das conexões & Fortes & $\begin{array}{l}\text { Oportunidade real — laços duradouros regidos } \\
\text { por instrumentos formais (contratos), num } \\
\text { ambiente regulado, traziam benefícios à gestão } \\
\text { da indústria e impactavam positivamente a } \\
\text { rentabilidade. }\end{array}$ \\
\hline \multirow[t]{2}{*}{ Natureza dos laços } & Colaborativa & $\begin{array}{l}\text { Oportunidade real — laços colaborativos, em } \\
\text { geral, com empresas do grupo, clientes, } \\
\text { fornecedores e o poder concedente. }\end{array}$ \\
\hline & Oportunista & $\begin{array}{l}\text { Ameaça real — laços com o regulador estadual } \\
\text { desenvolvidos caso a caso e, generalizadamente, } \\
\text { tensos, implicando ameaça real à indústria. }\end{array}$ \\
\hline
\end{tabular}

\begin{tabular}{|c|c|c|}
\hline \multicolumn{3}{|c|}{$\begin{array}{c}\text { Quadro } 6 \\
\text { Implicações estratégicas das alianças e redes da CEG e } \\
\text { da CEG RIO no nível da empresa }\end{array}$} \\
\hline Construtos & Indicadores & Implicações estratégicas no nível da empresa \\
\hline \multirow[t]{2}{*}{ Densidade } & Alta & $\begin{array}{l}\text { Força real — a grande quantidade de clientes } \\
\text { permitia às empresas deter um grande volume } \\
\text { de informações para ser usado nos seus } \\
\text { relacionamentos e na alavancagem de serviços } \\
\text { adicionais. }\end{array}$ \\
\hline & & $\begin{array}{l}\text { Fraqueza real — a obrigatoriedade de atender } \\
\text { clientes pouco rentáveis gerava custos de } \\
\text { atendimento indesejáveis, mas obrigatórios. }\end{array}$ \\
\hline
\end{tabular}




\begin{tabular}{|c|c|c|}
\hline Construtos & Indicadores & Implicações estratégicas no nível da empresa \\
\hline \multirow[t]{2}{*}{ Escopo } & Restrito: área de concessão & $\begin{array}{l}\text { Fraqueza potencial — - a restrição à atuação em } \\
\text { uma área de concessão implicava capacidade } \\
\text { de crescimento limitada, podendo levar à } \\
\text { acomodação na gestão, potencializando } \\
\text { desempenho inferior no longo prazo. }\end{array}$ \\
\hline & Amplo: laços globais & $\begin{array}{l}\text { Força real — fortes laços com outros ativos do } \\
\text { grupo (nacionais, na América do Sul e em } \\
\text { outras regiões do mundo), quer seja em termos } \\
\text { de alocação de recursos, quer seja em termos } \\
\text { de transferência de tecnologia e know-how de } \\
\text { gestão, contribuindo para um desempenho } \\
\text { superior. }\end{array}$ \\
\hline \multirow[t]{3}{*}{$\begin{array}{l}\text { Posição e centralidade } \\
\text { na rede }\end{array}$} & $\begin{array}{l}\text { Central no âmbito da área de } \\
\text { concessão }\end{array}$ & $\begin{array}{l}\text { Força real — grande acesso a recursos/ } \\
\text { informações e controle sobre as ações de } \\
\text { gestão operacional (técnica e comercial) em } \\
\text { função da alta centralidade na área de } \\
\text { concessão. Isso permitia acumular } \\
\text { informações, conhecimento de processos e } \\
\text { desenvolvimento de capacidades, contribuindo } \\
\text { para o melhor desempenho das empresas. }\end{array}$ \\
\hline & $\begin{array}{l}\text { Intermediária no âmbito do setor } \\
\text { de distribuiçãao de gás } \\
\text { canalizado no Brasil }\end{array}$ & $\begin{array}{l}\text { Força potencial — a posição de cada } \\
\text { concessionária de distribuição de gás } \\
\text { canalizado no Brasil foi considerada, em } \\
\text { princípio, baixa. No entanto, a posição da CEG } \\
\text { e da CEG RIO foi considerada intermediária, por } \\
\text { seu alinhamento com a GN SP Sul num bloco } \\
\text { de ativos de um forte grupo empresarial, } \\
\text { permitindo o acúmulo de informações e } \\
\text { experiências em prol da eficiência na gestão de } \\
\text { recursos/competências. }\end{array}$ \\
\hline & $\begin{array}{l}\text { Periférica no âmbito do setor } \\
\text { de gás no Brasil }\end{array}$ & $\begin{array}{l}\text { Fraqueza potencial — - baixa centralidade das } \\
\text { empresas na cadeia do gás, em função da } \\
\text { posição de dominância da Petrobras, com seus } \\
\text { múltiplos papéis e atuação em segmentos } \\
\text { monopolistas, implicando posição de } \\
\text { desvantagem nas negociações com a Petrobras } \\
\text { e na capacidade de competição com } \\
\text { energéticos substitutos. }\end{array}$ \\
\hline
\end{tabular}




\begin{tabular}{|c|c|c|}
\hline Construtos & Indicadores & Implicações estratégicas no nível da empresa \\
\hline & Central no setor de gás mundial & $\begin{array}{l}\text { Força potencial — a posição do grupo Gas } \\
\text { Natural, central no âmbito mundial de energia, } \\
\text { particularmente no de gás, permitiu às } \\
\text { empresas otimizar a alocação de recursos/ } \\
\text { competências, a absorção de tecnologias } \\
\text { específicas da distribuição de gás e a utilização } \\
\text { de know-how de gestão. }\end{array}$ \\
\hline Orifícios estruturais & Inexistentes & $\begin{array}{l}\text { Fraqueza potencial — inexistência de orifícios } \\
\text { estruturais, inibindo o desenvolvimento de } \\
\text { competências distintivas. }\end{array}$ \\
\hline Tipo de laços & Visíveis & $\begin{array}{l}\text { Fraqueza potencial — laços, em geral, visíveis } \\
\text { com empresas do grupo, clientes, } \\
\text { fornecedores, poder concedente e Agenersa, } \\
\text { por conta das características de serviço público } \\
\text { concedido, implicando diminuição de } \\
\text { vantagens competitivas informacionais ante os } \\
\text { energéticos substitutos. }\end{array}$ \\
\hline Equivalência estrutural & Não-equivalência & $\begin{array}{l}\text { Fraqueza potencial — inexistência de agentes } \\
\text { de relacionamento equivalente com os clientes, } \\
\text { não potencializando alianças que } \\
\text { proporcionassem informações estratégicas às } \\
\text { empresas. }\end{array}$ \\
\hline Padrão dos laços & Diretos e indiretos & $\begin{array}{l}\text { Força real — benefícios para as empresas em } \\
\text { função dos laços diretos (clientes, } \\
\text { fornecedores, regulador) e indiretos (poder } \\
\text { concedente, outras distribuidoras de gás) } \\
\text { múltiplos, permitindo conhecimento e atuação } \\
\text { únicos, implicando vantagem competitiva } \\
\text { diante de provedores de energéticos substitutos } \\
\text { e no relacionamento com o mercado cativo. }\end{array}$ \\
\hline $\begin{array}{l}\text { Identidade da empresa } \\
\text { focal }\end{array}$ & Forte e favorável & $\begin{array}{l}\text { Força real — identidade forte e favorável das } \\
\text { empresas na economia do estado do Rio de } \\
\text { Janeiro, em função da participação do gás na } \\
\text { matriz energética e da história centenária da } \\
\text { CEG. }\end{array}$ \\
\hline $\begin{array}{l}\text { Status da empresa } \\
\text { focal }\end{array}$ & Forte e favorável & $\begin{array}{l}\text { Força potencial — status forte e favorável das } \\
\text { empresas no segmento e na economia do } \\
\text { estado, permitindo desenvolver competências } \\
\text { políticas, regulatórias e institucionais. }\end{array}$ \\
\hline
\end{tabular}




\begin{tabular}{|c|c|c|}
\hline Construtos & Indicadores & Implicações estratégicas no nível da empresa \\
\hline $\begin{array}{l}\text { Força das } \\
\text { conexões }\end{array}$ & Fortes & $\begin{array}{l}\text { Força real — laços duradouros regidos por } \\
\text { instrumentos formais (contratos), regras num } \\
\text { ambiente regulado, trouxeram benefícios à } \\
\text { gestão das empresas e impactaram } \\
\text { positivamente a rentabilidade. }\end{array}$ \\
\hline \multirow[t]{2}{*}{ Natureza dos laços } & Colaborativa & $\begin{array}{l}\text { Força real — laços com empresas do grupo, } \\
\text { clientes, fornecedores e o poder concedente, } \\
\text { em geral colaborativos, permitindo o } \\
\text { desenvolvimento de ações de gestão que } \\
\text { agregaram vantagens competitivas. }\end{array}$ \\
\hline & Oportunista & $\begin{array}{l}\text { Fraqueza real — laços com o regulador } \\
\text { estadual caso a caso e, generalizadamente, } \\
\text { tensos, com desperdício de esforços e } \\
\text { recursos/competências. }\end{array}$ \\
\hline \multirow[t]{2}{*}{$\begin{array}{l}\text { Uso de mecanismos } \\
\text { de governança }\end{array}$} & Não-apropriado & $\begin{array}{l}\text { Fraqueza real — baixa incidência de } \\
\text { mecanismos formais de governança das } \\
\text { alianças desenvolvidas pelas empresas. }\end{array}$ \\
\hline & Apropriado & $\begin{array}{l}\text { Força real — movimento de consolidação de } \\
\text { mecanismos de controle de competências e de } \\
\text { qualidade de execução dos prestadores de serviços. }\end{array}$ \\
\hline $\begin{array}{l}\text { Desenvolvimento de } \\
\text { rotinas de } \\
\text { compartilhamento de } \\
\text { informações } \\
\text { interfirmas }\end{array}$ & $\begin{array}{l}\text { Baixo estágio de } \\
\text { desenvolvimento }\end{array}$ & $\begin{array}{l}\text { Fraqueza real — - baixa prontidão para o } \\
\text { desenvolvimento de rotinas de troca de } \\
\text { informações interfirmas, com exceção dos } \\
\text { prestadores de serviços terceirizados de } \\
\text { construção e manutenção da rede e de serviços } \\
\text { internos nos clientes. }\end{array}$ \\
\hline $\begin{array}{l}\text { Experiência com } \\
\text { múltiplas alianças }\end{array}$ & Extensa & $\begin{array}{l}\text { Força potencial — as experiências do grupo } \\
\text { Gas Natural com alianças em âmbito global } \\
\text { poderiam constituir maiores benefícios para o } \\
\text { desempenho da CEG e da CEG RIO. }\end{array}$ \\
\hline \multirow[t]{2}{*}{$\begin{array}{l}\text { Alinhamento de } \\
\text { interesses entre os } \\
\text { parceiros }\end{array}$} & Nível inadequado & $\begin{array}{l}\text { Fraqueza real — não foi evidenciado o } \\
\text { alinhamento de interesses entre o regulador } \\
\text { estadual e as concessionárias, o que implicava } \\
\text { fraqueza real para as empresas. Quanto à } \\
\text { Petrobras, também se percebeu uma divergência } \\
\text { de interesses, a despeito da participação } \\
\text { societária da Petrobras na CEG RIO. }\end{array}$ \\
\hline & Nível adequado & $\begin{array}{l}\text { Força real } — 0 \text { alinhamento de interesses com } \\
0 \text { poder concedente configurava força real. }\end{array}$ \\
\hline $\begin{array}{l}\text { Sistemas de medição } \\
\text { de desempenho da } \\
\text { rede }\end{array}$ & Não-apropriados & $\begin{array}{l}\text { Fraqueza real - com exceção de indicadores de } \\
\text { controle de qualidade de prestadores de serviços } \\
\text { técnicos, não foram identificados sistemas de } \\
\text { medição de desempenho de alianças. }\end{array}$ \\
\hline
\end{tabular}


Como destaque, a análise relacional expôs a complexidade dos relacionamentos das empresas com a Petrobras, em seus múltiplos papéis e sua posição predominante na cadeia brasileira do gás. Igualmente, emergiram com relevância os relacionamentos com parceiros fornecedores de serviços técnicos. O poder concedente e o órgão regulador também apareceram em destaque como atores estratégicos na ego-rede da CEG e da CEG RIO, evidenciando inúmeras oportunidades e ameaças no seu relacionamento.

\section{Discussão}

O bem-sucedido desempenho da CEG e da CEG RIO no período de 1998 a 2005 indicava que as empresas foram capazes de aproveitar com sucesso as oportunidades do macroambiente, ao alavancar as forças e minimizar as fraquezas de seus recursos/competências a partir de sua postura estratégica, evidenciando a adequação estratégica (fit). Basicamente, a estratégia das empresas foi função das diretrizes de internacionalização de seu controlador, o grupo Gas Natural, e ancorada em três principais pilares: orientação ao cliente, qualidade e rentabilidade (pela redução de custos e maximização de receitas).

O engajamento das empresas em projetos de responsabilidade social e sua condição de distribuidoras de "energia limpa" alinhavam-se à estratégia de comunicar à sociedade uma imagem positiva ligada ao desenvolvimento do estado do Rio de Janeiro e ao respeito ao meio ambiente. Isso contribuiu de forma qualitativa na caracterização da competitividade do gás natural em relação a outros energéticos substitutos.

Destacaram-se diversos exemplos da adequação estratégica das empresas, como no caso do foco nos clientes com diferenciação pela qualidade, ao explorarem-se as forças decorrentes das competências adquiridas pela transferência de tecnologias relativas à distribuição de gás natural canalizado do grupo Gas Natural. Tais forças foram alavancadas para atender as oportunidades de um enorme mercado potencial, inexplorado até a privatização das empresas, principalmente tratando-se dos clientes automotivos e industriais, além de expandir o seu mercado cativo, composto de clientes residenciais e comerciais. No entanto, também houve implicações estratégicas relativas ao macroambiente que não foram mitigadas de forma ideal, como é o caso da ameaça ao suprimento de gás (volume e preço) que sustente os planos de investimentos, e das incertezas quanto ao marco regulatório, fator de risco que, em direção contrária, postergava decisões de investimento.

A administração das empresas, com estilo centralizador, refletia o modelo de gestão internacional do grupo com influência direta na estrutura orga- 
nizacional, nos processos de negócios e na cultura organizacional da CEG e da CEG RIO. Não era percebida a intenção expressa de ser estabelecido um modelo de gestão mais participativo. No entanto, os indícios coletados apontaram para uma estrutura com poucos níveis hierárquicos e que era ágil o suficiente para responder às demandas internas e do macroambiente, principalmente no que tange ao atendimento de seus clientes existentes e potenciais.

Embora fosse percebida uma utilização da tecnologia da informação aquém das necessidades e potencialidades das empresas, reconhecia-se a intenção explícita de buscar a melhoria contínua dos processos de negócio com o uso intensivo de novas tecnologias. Essa tendência alinhava-se às posturas estratégicas de excelência de serviços e de redução de custos.

A máxima utilização de terceiros, política global do grupo Gas Natural, nos serviços de construção e manutenção da rede de gás, internos para clientes e de conversão do gás manufaturado para o gás natural trouxe significativos problemas no início do período de gestão privada das concessionárias. No entanto, houve evidências de que os problemas foram contornados, com a construção de alianças com tais fornecedores. Se num primeiro momento, o movimento de terceirização teve como principal direcionador a redução de custos, aos poucos foram sendo desenvolvidas parcerias com os fornecedores, tendo por base a qualidade dos serviços prestados construída com programas de capacitação conduzidos pelas concessionárias. Nesse processo, houve um natural ajuste do grupo de fornecedores, o que trouxe benefícios às partes.

O relacionamento com os fornecedores de serviços técnicos eram as alianças mais verdadeiramente estratégicas construídas pelas empresas, embora não houvesse evidências da consciência do grande potencial que as alianças e redes estratégicas pudessem proporcionar. Tanto em sua concepção quanto em sua execução, perceberam-se nesses relacionamentos características de alta densidade, padrão de laços diretos, identidades fortes e favoráveis, status fortes e favoráveis, natureza colaborativa e laços fortes, que constituíam forças da CEG e da CEG RIO, à luz da estratégia de terceirização. O crescente desenvolvimento de mecanismos para gestão dessas alianças, por meio do controle sobre as qualificações da força de trabalho terceirizada, assim como do monitoramento da eficiência e qualidade dos serviços prestados, era uma expressão inequívoca de gestão de alianças estratégicas. Também puderam ser evidenciadas alianças com fornecedores de equipamentos, para execução de ações de marketing e de comercialização conjunta.

Quanto ao relacionamento com o governo do estado do Rio de Janeiro e demais órgãos governamentais, atores muito importantes da rede de valor das empresas, dada sua condição de concessões públicas, evidenciaram-se alianças estratégicas. Os aditivos aos contratos de concessão, que estipularam as 
metas de ampliação do fornecimento de gás do estado, são exemplos de laços colaborativos formais. Mas, também, evidenciaram-se alianças informais, expressas na imagem de colaboração crescente entre as empresas e o governo, bastante explorada na mídia.

O mesmo não aconteceu com outros importantes atores da rede de valor das empresas: a Petrobras e a Agenersa. Não se evidenciou uma orquestração estratégica dos relacionamentos existentes com a Petrobras. Os relacionamentos foram sendo construídos caso a caso, sem uma visão integrada e relacional, apesar de a Petrobras desempenhar múltiplos e importantes papéis na egorede da CEG e da CEG RIO - por exemplo, fornecedor único de gás, rival (com a competição de seus energéticos substitutos ao gás natural) e acionista (da CEG RIO). Embora os diversos relacionamentos com a Petrobras ocorressem de forma geralmente amistosa e produtiva, havia indícios de baixo aproveitamento de oportunidades, assim como evidências de que ameaças, como a limitação da estratégia de expansão da CEG e da CEG RIO em relação à capacidade de investimentos da Petrobras, não estavam sendo apropriadamente mitigadas.

O relacionamento com o órgão regulador estadual (Agenersa) foi sempre difícil e não havia indícios de que as empresas estivessem conseguindo tratar plenamente as ameaças e alavancar as oportunidades do macroambiente político, a despeito do mencionado relacionamento amistoso e produtivo com o poder concedente. Não havia evidências de uma postura estratégica consistente no sentido de obter vantagens competitivas das "janelas políticas" decorrentes do marco regulatório em formação. Foi revelada uma atuação caso a caso no âmbito regulatório que, se não trouxe impacto negativo no desempenho das empresas até então, poderia trazê-lo no futuro. Os resultados da primeira revisão tarifária qüinqüenal, que não foram ruins para as empresas, exemplificaram bem esse risco. A metodologia empregada na primeira revisão qüinqüenal, na visão das empresas, não encontra respaldo nos contratos de concessão vigentes, o que leva incertezas às revisões subseqüentes.

Foi constatado que a atuação do regulador estadual, tanto técnica quanto politicamente, no âmbito de suas atribuições regulatórias, deixou muito a desejar. Mas não se constatou a intenção de estabelecer um relacionamento estrategicamente orientado a aproveitar as forças das empresas (a qualidade dos serviços, por exemplo), com o intuito de explorar as oportunidades emergentes de um marco regulatório parcialmente indefinido e de mitigar as ameaças da atuação ainda pouco consistente do órgão regulador.

Nesse contexto, não se pôde confirmar uma postura definida das empresas quanto ao marco regulatório, segundo a tipologia de Bailey (1997). As respostas ao questionário de percepções e as entrevistas complementares indicaram que, embora sejam esperadas obrigações regulatórias econômicas, soci- 
ais e ambientais crescentes, não há evidências de uma postura explícita e proativa diante do ambiente regulatório, em formação e incerto. As ações são normalmente tomadas caso a caso em função das demandas dos assuntos regulatórios nos âmbitos nacional e regional.

Foi evidenciada a importância das implicações estratégicas dos fatores macroambientais para o desempenho da CEG e da CEG RIO. Dos 28 fatores macroambientais destacados para avaliação de seu grau de importância, nada menos que 27 foram percebidos por mais de 70\% dos pesquisados como importantes ou muito importantes. Além disso, foram identificadas 31 ameaças reais ou potenciais do macroambiente, contra 21 oportunidades reais e potenciais. Os dois fatores macroambientais mais relevantes contribuindo para o ambiente de incertezas que envolvia as empresas, e cujo tratamento estratégico não pôde ser percebido com clareza, foram: o suprimento de gás e a configuração do marco regulatório do setor de gás natural. Quanto ao segundo, destaque-se a percepção de que havia influência média ou alta de ideologias nas decisões políticas, legislativas e judiciárias (84,6\% dos respondentes) e de que a capacidade técnica das instituições que impactavam as empresas, tanto positiva quanto negativamente, como os órgãos reguladores, era média ou baixa (77\% dos respondentes). A importância desses fatores ficou ainda mais evidente a partir dos riscos crescentes de abastecimento (volume e preço) de gás natural no Brasil e pela discussão oriunda dos projetos de lei em tramitação no Congresso Nacional, com efeito no marco regulatório do gás natural.

A previsibilidade dos riscos ao abastecimento era grande, o que tornava a avaliação prévia de seus impactos, realizada tanto no âmbito governamental quanto no âmbito empresarial, um ponto falho. Uma boa formulação estratégica deveria ter trazido à tona de uma forma mais efetiva tal cenário. Não há claras evidências de que tenha sido esse o caso.

O estudo revelou que a atuação da CEG e da CEG RIO vinha se mantendo bastante alinhada às suas estratégias declaradas (visão, missão, valores, objetivos, metas etc.) e que essas estratégias vinham sendo capazes de levar ao desempenho esperado. Portanto, não se encontraram inconsistências na administração das empresas, do ponto de vista estratégico. Ainda assim, houve várias evidências de que, a despeito das incertezas do macroambiente, nitidamente o político, as empresas se defrontavam com oportunidades que talvez pudessem ter sido mais bem aproveitadas. A análise relacional apontou uma baixa gestão estratégica das alianças existentes.

A alavancagem das forças constituídas pelos fatores organizacionais (exemplos: know-how internacional, alianças com prestadores de serviços, capacidade técnica e financeira de investimentos, sistemas educacionais, processos e sistemas específicos para o negócio, capacidade de influência e articulação 
política etc.) e a minimização das fraquezas (exemplos: processo decisório centralizado, uso de tecnologia da informação aquém do ideal, gestão de relacionamentos caso a caso etc.) poderiam ser ainda mais bem direcionadas para a mitigação das ameaças, segundo as evidências cobertas por esta pesquisa.

O uso do modelo SNA não modificou substancialmente o resultado da análise integrativa tradicional a respeito da adequação estratégica das empresas, mas trouxe contribuições significativas da perspectiva relacional. Puderam ser confirmadas e, em alguns casos, ressaltadas questões levantadas na análise tradicional. Em suma, o que mais se destacou na análise relacional foi a potencialidade inexplorada de importantes insights que ela possa trazer para a formulação estratégica das empresas.

\section{Conclusão e recomendações}

O estudo atingiu seu objetivo principal de aplicar em empresas concessionárias de serviços públicos (CEG e CEG RIO), os modelos genérico integrativo e relacional para avaliação da adequação estratégica. Se a análise relacional conferiu luz à avaliação das implicações no desempenho das empresas pesquisadas em função dos fatores macroambientais que as envolviam, problema central deste estudo, percebeu-se também o quanto era limitada a prontidão das empresas para a gestão estratégica com base em alianças e redes.

Evidenciou-se a potencialidade das alianças estratégicas para a minimização das ameaças de fatores macroambientais econômicos e políticos, ao explicitarem-se os laços já desenvolvidos e suas características atuais. Pode-se também afirmar que é muito relevante a análise da gestão estratégica de empresas em ambientes supostamente beneficiados por mercados cativos. Mostrou-se que a CEG e a CEG RIO possuem rivais em sua arena competitiva, e que o fato de estarem sujeitas a um ambiente em mudança e incerto, onde se destaca um marco regulatório incompleto, só agrega importância a um processo amplo e profundo de formulação e realização de estratégias. As características do seu mercado competitivo, que implica investimentos por parte dos clientes para conversão de suas fontes de energia para o gás, e um comprometimento de médio e longo prazos com as distribuidoras por contratos de fornecimento, lhe conferiam grande potencial de estabelecimento de alianças duradouras.

Como contribuição para estudos futuros em indústrias reguladas, num contexto de serviços públicos concedidos, sugere-se considerar construtos pertinentes específicos. Para o modelo GI, este estudo demonstrou a necessidade de variáveis específicas de sistemas de informação regulatórios e de gestão da 
força de trabalho terceirizada na categoria organização soft, assim como de variáveis específicas de capacitação em relações políticas, institucionais e regulatórias na categoria pessoas. Com relação ao modelo SNA, apontou-se a necessidade de desenvolver indicadores específicos para representar as condições dos laços mandatórios decorrentes das obrigações regulatórias econômicas, sociais e ambientais características de concessões de serviços públicos. Tais construtos não foram desenvolvidos no âmbito desta pesquisa em função do baixo grau de maturidade do ambiente regulatório em questão e da baixa prontidão das empresas para a gestão estratégica em alianças e redes. Dessa forma, considerou-se que essa seja uma sugestão para aprofundamento em pesquisas posteriores, nesse ou em outros setores, que tenham um ambiente regulatório mais estável.

Entre os resultados mais significativos deste estudo, destaca-se a constatação da consistência entre a estratégia declarada das empresas e sua realização, com impacto positivo no seu desempenho. Também é significativa, e extensiva a outras empresas afetadas pelo setor focado neste artigo, a constatação de que há riscos aos negócios decorrentes das ameaças não-mitigadas dos fatores macroambientais, principalmente os políticos e econômicos, notadamente a disponibilidade e confiabilidade de abastecimento e o marco regulatório. $\mathrm{O}$ estabelecimento de alianças estratégicas para o aproveitamento de "janelas políticas" não foi, ainda, concebido e realizado em benefício do desempenho das empresas. No entanto, as bem-sucedidas alianças de natureza estratégica com fornecedores, complementors, clientes e o poder concedente indicam caminhos a ser desenvolvidos no relacionamento com a Petrobras, com órgãos reguladores, com rivais e demais membros da ego-rede das empresas.

Um ambiente de incertezas não é, necessariamente, fonte de ameaças; pode também trazer oportunidades aos negócios. O fato de o marco regulatório estar incompleto também pode possibilitar benefícios às empresas. O setor de distribuição de gás canalizado é naturalmente estruturado em rede. Fazer dessa rede de relacionamentos, na maioria dos casos obrigatórios por lei, um conjunto estrategicamente gerido é um desafio explicitado de forma irrefutável pela perspectiva relacional.

\section{Referências bibliográficas}

AUSTIN, J. E. Managing in developing countries: strategic analysis and operating techniques. New York: The Free Press, 1990.

BAILEY, E. Integrating policy trends into dynamic advantages. In: DAY, G. S.; REIBSTEIN, D. J.; GUNTHER, R. (Eds.). Wharton on dynamic competitive strategy. New York: John Wiley \& Sons, 1997. 
BAUMOL, W. J.; PANZAR, J. C.; WILLING, R. D. Contestable markets and the theory of industry structure. New York: Harcourt Brace Jovanovich, 1982.

BRADENBURGER, A. M.; NALEBUFF, B. J. Co-opetition. New York: Doubleday, 1997.

BRASIL. Constituição Federal, de 5 de outubro de 1988.

. Lei Federal n. 9.478, de 6 de agosto de 1997. Dispõe sobre a política energética nacional, as atividades relativas ao monopólio do petróleo, institui o Conselho Nacional de Política Energética e a Agência Nacional do Petróleo e dá outras providências.

CEG (Companhia Estadual de Gás do Rio de Janeiro). Demonstrações financeiras padronizadas 1998. Rio de Janeiro: CVM, 1999.

. Demonstrações financeiras padronizadas 1999. Rio de Janeiro: CVM, 2000.

. Demonstrações financeiras padronizadas 2000. Rio de Janeiro: CVM, 2001.

. Demonstrações financeiras padronizadas 2001. Rio de Janeiro: CVM, 2002.

. Demonstrações financeiras padronizadas 2002. Rio de Janeiro: CVM, 2003.

. Demonstrações financeiras padronizadas 2003. Rio de Janeiro: CVM, 2004.

. Relatório anual 2004. Rio de Janeiro: CEG, 2005.

. Demonstrações financeiras padronizadas 2005. Rio de Janeiro: CVM, 2006.

CEG e CEG RIO. Plano de gás natural do estado do Rio de Janeiro. Rio de Janeiro: CEG e CEG RIO, 2002.

. Cinco anos de gestão: 1997-2002. Rio de Janeiro: CEG e CEG RIO, 2003.

CEG RIO. Relatório anual 1999. Rio de Janeiro: CEG, 2000.

. Relatório anual 2000. Rio de Janeiro: CEG, 2001.

. Relatório anual 2001. Rio de Janeiro: CEG, 2002.

. Relatório anual 2002. Rio de Janeiro: CEG, 2003.

. Relatório anual 2003. Rio de Janeiro: CEG, 2004.

. Relatório anual 2004. Rio de Janeiro: CEG, 2005.

. Relatório anual 2005. Rio de Janeiro: CEG, 2006.

CHERNS, A. B. The principles of socio-technical design. Human Relations, n. 29, p. 783792, 1976. 
CONTRACTOR, F. J.; LORANGE, P. Why should firms cooperate? The strategy and economics basis for cooperative ventures. In: . Cooperative strategies in international business. Lexington, M.A: Lexington Books, 1988.

COUTINHO, R.; MACEDO-SOARES, T. D. L. v. A. Gestão estratégica com responsabilidade social: arcabouço analítico para auxiliar sua implementação em empresas no Brasil. Revista de Administração Contemporânea, v. 6, n. 3, p. 75-96, 2002.

DAY, G. S.; REIBSTEIN, D. J.; GUNTHER, R. E. (Eds.). Wharton on dynamic competitive strategy. New York: John Wiley \& Sons, 1997.

FAHEY, L.; RANDALL, R. M. Learning from the future. New York: John Wiley, 1998.

FIGUEIRA, L. A. P. A. Estratégias para a geração de energia nucleoelétrica no Brasil. 2004. Dissertação (Mestrado) - Departamento de Administração, Pontifícia Universidade Católica do Rio de Janeiro, Rio de Janeiro.

GALASKIEWICZ, J.; ZAHEER, A. Networks of competitive advantage. Research in the Sociology of Organizations, v. 16, p. 237-261, 1999.

GOMES-CASSERES, B. Group versus group: how alliance networks compete. Harvard Business Review, p. 62-74, July/Aug. 1994.

GOMES-CASSERES, B. The alliance revolution. Cambridge: Harvard University Press, 1996.

GRANT, R. M. Contemporary strategy analysis: concepts, techniques, applications. Oxford: Blackwell Publishers, 1998.

GULATI, R. Alliances and networks. Strategic Management Journal, v. 19, p. 293-317, 1998.

GULATI, R.; NOHRIA, N.; ZAHEER, A. Strategic networks. Strategic Management Journal, v. 21 , p. $203-215,2000$.

HOFER, C.; SCHENDEL, D. E. Strategy formulation: analytical concepts. West, St. Paul MN, 1978.

KALE, P.; SINGH, H.; PERLMUTTER, H. Learning and protection of proprietary assets in strategic alliances: building relational capital. Strategic Management Journal, v. 21, p. 217237, 2000. Special issue.

KNOKE, D. Changing organizations - business networks in the new political economy. Boulder, CO: Westview, 2001.

MACEDO-SOARES, T. D. L. v. A. An integrative model for strategic management analysis: application to organizations in Brazil. In: INFORMS-KORMS CONFERENCE, 2000. Proceedings... Seoul, Korea, 2000, p.460-467.

Strategic alliances and networks: conceptual tools for strategic assessments. In: Readings Book of GBATA International Conference 2002, Rome: St. John's University, 2002. v. 1, p. 292-305. 
; CHAMONE, S. G. Total quality strategies in industry. Quality Management Journal, v. 1, n. 3, p. $57-79,1994$.

; FIGUEIRA, L. A. P. A. Estratégia de geração de energia nuclear no Brasil: o caso da Eletronuclear. RAP, v. 38, n. 1, 2004.

; LUCAS, D. C. Práticas gerenciais de qualidade das empresas líderes no Brasil. Rio de Janeiro: Qualitymark, 1996.

; TAUHATA, T. Ferramental para análise estratégica pela ótica relacional: resultados do seu teste piloto na Companhia Vale do Rio Doce. In: ENCONTRO ANUAL DA ANPAD, 26., Salvador, 2002. Anais... Salvador: Universidade Federal da Bahia, 2002.

MELO FILHO, M. A história do gás: do Rio de Janeiro para o Brasil. Rio de Janeiro: Gerex/ CEG, 2005.

MINTZBERG, H. Generic strategies: toward a comprehensive framework. Advances in strategic management. JAI Press, v. 5, p. 1-67, 1988.

NOHRIA, N.; GARCIA-PONT, C. Global strategic linkages and industry structure. Strategic Management Journal, v. 12, p. 105-124, 1991.

PARISE, S. The effects of resource exchange and partner roles on alliance performance. Thesis $(\mathrm{PhD})$ - Boston University, Boston, 2000.

PORTER, M. E. Competitive strategy: techniques for analyzing industries and competitors. New York: Free Press, 1980.

POSSAS, M. Regulação e incentivo à competição. In: SARAIVA, E.; PECI A.; BRASÍLICO, E. A. Regulação, defesa da concorrência e concessões. Rio de Janeiro: FGV, 2002.

REA, L. M.; PARKER, R. A. Metodologia de pesquisa: do planejamento à execução. São Paulo: Pioneira, 2000.

RIO DE JANEIRO. Constituição Estadual, de 5 de outubro de 1989.

RIOGÁs. Relatório anual 1998. Rio de Janeiro: CEG, 1999.

ROCHA, B. Formulação e implementação de políticas públicas: desenho institucional. In: ROCHA, B. (Org.). A regulação da infra-estrutura no Brasil - balanço e propostas. São Paulo: IOB Thomson, 2003.

TAUHATA, T. Implicações estratégicas das redes de relacionamento: estudo de caso da unidade de minério de ferro da Cia. Vale do Rio Doce. 2002. Dissertação (Mestrado) — Departamento de Administração, Pontifícia Universidade Católica do Rio de Janeiro, Rio de Janeiro.

WERNERFELT, B. A. A resource-based view of the firm. Strategic Management Journal, v. 5, n. 2, p. 171-180, 1984.

YIN, R. K. Case study research — design and methods. London: Sage Publications, 1994. 